\title{
CORROSÃO EM TUBOS DE COBRE UTILIZADOS EM REDES DE SPRINKLERS
}

\author{
Sidney Oswaldo Pagotto Júnior (1) \\ Zehbour Panossian (2) \\ Silvia Verina Neves de Freitas (3)
}

\section{Resumo}

Nos últimos anos, falhas em tubos de cobre têm ocorrido com freqüência em redes de chuveiros automáticos para combate a incêndio (rede de sprinklers). Estas ocorrem devido à ocorrência de corrosão localizada na superfície interna da tubulação de cobre, gerando perfuraçōes e trazendo transtornos aos usuários. Com o intuito de analisar as possíveis causas deste problema, técnicos do Agrupamento de Corrosão e Proteção do IPT realizaram uma série de ensaios e análises, cujos resultados indicam que os fatores determinantes para a ocorrência deste tipo de processo corrosivo são: falta de circulação de água na rede de sprinkJers, presença de sujidades no interior da tubulação e uso de fluxo de solda em excesso. A primeira parte deste trabalho apresenta uma análise de um caso de corrosão ocorrido recentemente, caracterizando o tipo de problema descrito. A segunda parte apresenta a metodologia adotada e os resultados obtidos em ensaios de simulação realizados em laboratório. Verificou-se que a presença de fluxo de solda em excesso prejudica a formaçẫo de uma camada de óxidos de características protetoras na superfície interna da tubulaçâo, afetando assim a sua resistência à corrosão.

Palavras-chave: Cobre; Corrosão; Fluxo de solda.

\section{Study of the Influence of the Application of Soldering Flux in the Corrosion of Copper Pipes}

\begin{abstract}
Failures in copper pipes used in fire sprinkler systems have been occurring frequently. They usually occur due to localized corrosion of the internal surface of the copper piping. In order to analyze the causes, Agrupamento de Corrosão e Proteção/IPT technicians made a series of tests and analyses. The results indicate that the decisive factors are: the lack of circulation of water in the fire sprinkler systems, the presence of dirt and excess soldering flux. This paper presents a case history and shows the results of simulation tests made at the Laboratory. The excess of soldering flux doesn't permit the formation of a protective layer of corrosion products, which is essential for copper tubes corrosion resistance.
\end{abstract}

Key-words: Copper; Corrosion; Soldering flux.

\section{INTRODUÇÃO}

Nos últimos anos, o Agrupamento de Corrosão e Proteção do IPT realizou diversos estudos nos quais verificou que vazamentos em tubos de cobre, decorrentes de processos de corrosão localizada, acarretaram sérios problemas aos seus usuários. $O$ presente trabalho tem por objetivo:
- apresentar um caso prático de falha em tubulação de cobre ocorrido em um prédio comercial, no qual o uso excessivo de fluxo de solda causou o processo corrosivo; e

- presentar os resultados obtidos em ensaios realizados em laboratório, por um período de dois anos, visando avaliar a influência da circulação de água no interior da tubulação de cobre e o efeito do uso excessivo de fluxo na corrosão destes tubos.

\footnotetext{
(1) Mestre, Pesquisador - Instituto de Pesquisas Tecnológicas do Estado de S. Paulo

(2) Doutora, Chefe de Agrupamento - Instituto de Pesquisas Tecnológicas do Estado de S. Paulo

(3) Técnica em Metalurgia - Instituto de Pesquisas Tecnológicas do Estado de S. Paulo
} 


\section{FALHA EM TUBULAÇÃO DE SPRINKLERS}

\section{I Materiais e Métodos}

Após três anos da instalação da tubulação de cobre (rede de sprinklers e rede de água potável) em um prédio comercial localizado na cidade de São Paulo, perfuraçốes ocorreram na rede de sprinklers. Foram verificados vazarnentos em diferentes andares do prédio, não sendo constatados problemas na rede de água potável. Para determinar as origens destas falhas, foram retiradas as amostras dos tubos da rede de sprinklers e da água retida no interior da tubulação da rede de sprinklers e armazenada na caixa d'água (água de abastecimento público que serve a rede de sprinklers).

Foram realizados os seguintes ensaios e análises:

- nos tubos: exame visual, exame metalográfico, análise química qualitativa dos elementos presentes nos produtos de corrosão por energia dispersiva, análise química para determinação dos compostos presentes nos produtos de corrosão por difratometria de raios $\mathrm{X}$;

- nas águas: análise química.

\subsection{Resultados}

O exame visual realizado no interior dos tubos coletados permitiu verificar a presença de uma camada de produtos de corrosão de cor escura cobrindo toda a superfície interna. Em alguns pontos, ocorreu destacamento desta camada, expondo o substrato metálico. Também foi observada a presença de uma mancha longitudinal na região central de um dos hemi-cilíndros, na borda da qual havia vários pontos de corrosão esverdeados, além de alguns pites (ver Figura I). A presença desta mancha foi atribuída ao arraste de material que ficou retido no interior da tubulação após a sua instalação.

Tabela I. Análise por energia dispersiva no interior do tubo de cobre

\begin{tabular}{|c|c|c|}
\hline Região analisada & Elementos identificados & Aspecto visual da região \\
\hline Região escura (RE) & $\begin{array}{l}\text { Oxigênio, cobre, alumínio, } \\
\text { silício, enxofre, chumbo, } \\
\text { cálcio e zinco }\end{array}$ & \\
\hline Pite (P) & Oxigênio, cobre, enxofre e cloro & \\
\hline
\end{tabular}

Nota: o elemento carbono que aparece nas análises não foi considerado pois a análise realizada sempre o detecta, estando este presente ou näo.

Tabela 2. Resultados da análise qualitativa por difratometria de raios- $X$.

\begin{tabular}{lcc}
\hline Região analisada & Compostos presentes & Aspecto visual da região \\
\hline $\begin{array}{l}\text { Produto verde } \\
\text { presente na }\end{array}$ & Óxido de Cobre I (Cuprita) & \\
superfície interna & Carbonato básico & de cobre (II) (Malaquita) \\
do tubo da rede & Óxido de Cobre II (Tenorita) & \\
de sprinklers & $\begin{array}{c}\text { Cloreto Básico de Cobre (II) } \\
\text { hidratado (Calumetita) }\end{array}$ & \\
& Cobre metálico & \\
& &
\end{tabular}

No exame metalográfico realizado nas seçốes transversais dos tubos de cobre da rede de sprinkJers, verificou-se a presença de regiōes com corrosão localizada e de pites perfurantes, que se iniciavam na superfície interna dos tubos (ver Figura 2).

Analisando a superfície interna das amostras de tubo de cobre por energia dispersiva, verificou-se a presença de picos elevados de oxigênio, cobre, alumínio, silício, enxofre, chumbo, cloro, cálcio e zinco (Tabela I). Destes, destacam-se o cloro e o zinco, provavelmente oriundos do fluxo de solda utilizado na soldagem da tubulação, pois é muito comum a adição de cloreto de zinco e amônia em fluxos de solda.

$A$ análise por difratometria de raios $X$ realizada nos produtos de corrosão presentes na superfície interna da tubulação, apresentada na Tabela 2, permitiu verificar a presença de óxido

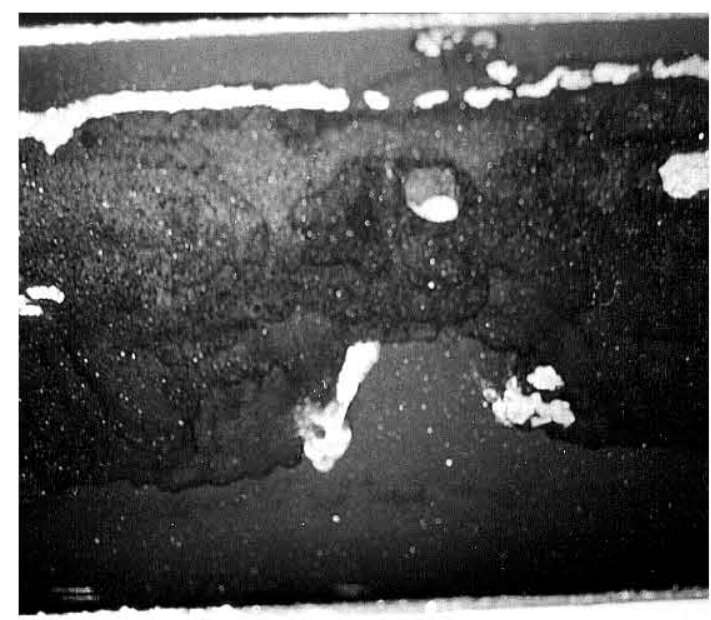

Figura I. Aspecto visual da superfície interna de um tubo da rede de sprinklers. Observam-se marcas de escorrimento (A) e pites nas bordas da mancha $(B)$.

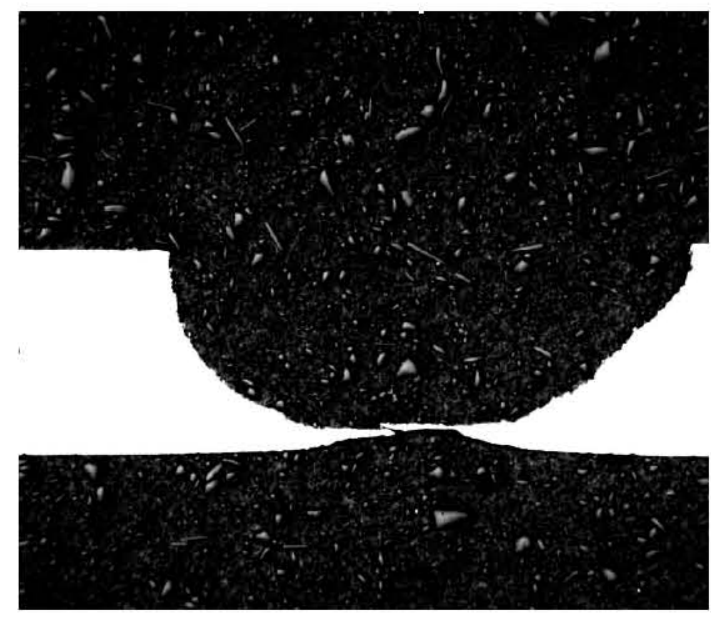

Figura 2. Aspecto visual da seção transversal de um tubo da rede de sprinklers. Observa-se ocorrência de corrosão iniciada no lado interno do tubo. 
de cobre I e II, carbonato de cálcio e cloreto básico de cobre. O carbonato de cál cio presente pode ser resultado da carbonatação do hidróxido de cálcio (comumente presente no cimento), cuja presença provavelmente foi devida a resíduos deixados no interior dos tubos durante sua instalação. A presença de cloreto de cobre foi atribuída à reação do material do tubo com o cloreto presente no fluxo de solda.

A Tabela 3 apresenta a análise das amostras de água colhidas de um sprinkler e da saída da caixa d'água. Pode-se constatar que a água retida no interior da rede de sprinklers apresentou um $\mathrm{pH}$ mais alcalino $(9, \mathrm{I})$ do que a água da caixa d'água $(8,4)$. Também foi possível verificar que a água colhida na tubulação da rede de sprinklers apresentou menor teor de sulfatos e maior teor de íons cloreto, se comparada à água colhida na caixa d'água. $\mathrm{O}$ maior teor de cloretos foi atribuído ao excesso de fluxo de solda presente no interior do tubo, pois, conforme já comentado anteriormente, é comum a adição de cloreto de zinco e amônia em fluxos de solda.

\section{ENSAIOS EM LABORATÓRIO}

\section{I Materiais e Métodos}

Para simular as condiçōes de instalação e utilização de uma rede de sprinklers, foram realizados ensaios simulando redes com e sem circulação de água, em duas situações distintas: com fluxo de solda aplicado corretamente e com fluxo aplicado em excesso. Desta forma, foram montados quatro ensaios: tubos soldados com fluxo aplicado corretamente e com circulação de água (redel), tubos soldados com fluxo aplicado corretamente e sem circulação de água (rede 2), tubos soldados com excesso de fluxo e com circulaçẫo da água (rede 3) e tubos soldados com excesso de fluxo, sem circulação de água (rede 4).

\subsection{Resultados}

A água a ser introduzida na tubulação foi analisada. Após 30 dias de ensaio, a água retida nas redes 2 e 4, que permaneceram fechadas, foi analisada, para comparação. De acordo com os dados apresentados na Tabela 4, verificou-se aumento significativo no teor de íons cloreto,
Tabela 3. Resultados da análise química realizada nas amostras de água colhidas de um sprinkler e da caixa d'água

\begin{tabular}{|c|c|c|}
\hline \multirow[t]{2}{*}{ Aspecto analisado } & \multicolumn{2}{|c|}{ Ponto de coleta da amostra } \\
\hline & Caixa d'água & Sprinkler \\
\hline $\mathrm{pH}\left(\mathrm{a} 21,6^{\circ} \mathrm{C}\right)$ & 8,4 & 9,1 \\
\hline Alcalinidade a fenolftaleína, em mg CaCO$/ / \mathrm{L}$ & 0,0 & 2,4 \\
\hline Alcalinidade ao metilorange, em $\mathrm{mg} \mathrm{CaCO} / \mathrm{L}$ & 25,7 & 28,5 \\
\hline Bicarbonato $\left(\mathrm{HCO}_{3}^{-}\right)$, em $\mathrm{mg} / \mathrm{L}^{*}$ & 31,4 & 34,8 \\
\hline Dureza total, em $\mathrm{mg} \mathrm{CaCO}_{3} / \mathrm{L}$ & 26,1 & 26,1 \\
\hline Ílons cloreto $\left(\mathrm{Cl}^{\prime}\right)$, em $\mathrm{mg} / \mathrm{L}$ & 5,9 & 7,3 \\
\hline ĺons sulfato ( $\mathrm{SO} 42^{-}$), em mg/L & 7,1 & 6,2 \\
\hline Cobre $(\mathrm{Cu})$, em $\mathrm{mg} / \mathrm{L}$ & $<0,5$ & $<0,5$ \\
\hline Ferro $(\mathrm{Fe}), \mathrm{em} \mathrm{mg} / \mathrm{L}$ & $<1,0$ & $<1,0$ \\
\hline
\end{tabular}

Nota: Valor calculado a partir da alcalinidade ao metilorange

zinco, amônia, ferro e sólidos dissolvidos. Este aumento foi significativamente maior na amostra de água onde o fluxo foi aplicado de forma descuidada no tubo, em relação à água colhida na tubulação onde o fluxo foi aplicado corretamente.

Após dois anos de ensaio, as quatro redes foram desmontadas. Os tubos destas redes foram secionados em sua seção longitudinal e examinados visualmente, sendo observado que:

- na rede I (fluxo aplicado corretamente, água circulando), formou-se uma camada de produtos de corrosão esverdeados, cobrindo toda a superfície interna dos tubos (Figura 3);

- na rede 2 (fluxo aplicado corretamente, sem circulaçăo), formou-se uma camada de produtos de corrosão negra, cobrindo todo o interior da tubulação, com exceção dos locais onde ocorreu escorrimento do fluxo de solda. Nestes locais, havia apenas uma fina camada de óxidos incolor (Figura 3);

- na rede 3 (fluxo em excesso, água circulando), formaram-se diversos tipos de produtos de corrosão: verdes, marrons e incolores. Em um trecho dos tubos, verificou-se a presença de pontos escuros, com destacamento dos produtos de corrosão esverdeados (Figura 4);

- na rede 4 (fluxo em excesso, sem circulação), formou-se uma carnada de produtos de corrosão fina e transparente, além de um trecho onde houve escorrimento do material de solda, devido ao excesso de fluxo utilizado (Figura 4).

Para determinar os elementos químicos presentes nos produtos de corrosão formados, foram realizadas análises por energia dispersiva em corpos-de-prova retirados dos tubos de cobre, cujos resultados estão apresentados na Tabela 5. Na rede I (fluxo correto, com circulação), detectou-se uma pequena quantidade de cloro e um pico significativo de oxigênio, devido a

Tabela 4. Análise química da água (ensaios em laboratório)

\begin{tabular}{lccc}
\hline \multicolumn{1}{c}{ Ensaios } & \multicolumn{3}{c}{ Amostra de água } \\
\hline & Inicial & Rede 2 & Rede 4 \\
\hline Sólidos Dissolvidos, em ppm & 71,8 & 204,3 & 1252,5 \\
Amônia $\left(\mathrm{NH}_{4}^{+}\right)$, em ppm & 0,9 & 1,6 & 10,2 \\
Ferro (Fe), em ppm & 0,0 & 1,7 & 0,8 \\
Zinco $(\mathrm{Zn})$, em ppm & 0,0 & 39,1 & 439,5 \\
Cobre $(\mathrm{Cu})$, em ppm & 0,0 & 0,3 & 0,4 \\
ĺons cloreto $\left(\mathrm{Cl}^{-}\right)$, em ppm & 10,2 & 66,0 & 542,2 \\
\hline
\end{tabular}

Tecnologia em Metalurgia e Materiais, Säo Paulo, v.2, n.1, p. 24-29, jul.-set. 2005 
Tabela 5. Análise por energia dispersiva na superfície interna dos tubos de cobre das redes I a 4.

\begin{tabular}{lll}
\hline Regiäo analisada & Rede & \multicolumn{1}{c}{ Elementos identificados } \\
\hline Interior do tubo & I & Oxigênio, cobre, alumínio, silício, fósforo, cloro, cálcio e ferro \\
Interior do tubo & 2 & Oxigênio, cobre, silício e enxofre \\
Interior do tubo & 3 & Oxigênio, cobre, alumínio, silício, fósforo, cloro, cálcio, ferro e zinco \\
Interior do tubo & 4 & Oxigênio, cobre, alumínio, silício, enxofre, cloro, cálcio e ferro \\
\hline
\end{tabular}

Nota: o elemento carbono que aparece nas análises não foi considerado pois a análise realizada sempre o detecta, estando este presente ou não.

grande quantidade de produtos de corrosão verdes formados. $\mathrm{Na}$ rede 2 (fluxo correto, sem circulação), onde se formou uma camada de óxidos escura, havia predominantemente cobre e uma quantidade bem menor de oxigênio, comparando com a amostra anterior. A rede 3 (fluxo em excesso, com circulação) apresentou os elementos cloro e zinco nos produtos de corrosão verdes, marrons e incolores. Sua presença foi atribuída ao fluxo de solda utilizado, que contém cloreto de zinco e de amônia. Na rede 4 (fluxo em excesso, sem circulação), constatou-se a presença significativa do elemento cloro, provavelmente devido à aplicação do fluxo em excesso. Um fato interessante é a presença significativa dos elementos silício, alumínio, cálcio, fósforo e ferro nas amostras onde houve circulação de água. No caso das amostras sem circulação, a presença destes elementos foi pouca ou mesmo nenhuma. Pode-se assim atribuir a presença destes elementos à composição da água que circulou no interior da tubulação.

Os ensaios realizados permitiram constatar que a aplicação descuidada do fluxo de solda causa uma alteração considerável nas características da água que fica retida no interior da tubulação. No caso do aumento na presença de sólidos dissolvidos, por exemplo, como a água em redes de sprinklers fica estagnada, a precipitação destes sólidos pode causar o acúmulo de sujidades no interior da tubulação, favorecendo a formação de pites. O aumento de íons cloreto também é preocupante, pois, embora haja controvérsias sobre seu efeito, alguns autores ${ }^{(1)}$, atribuem a formaçâo de pites a um aumento no teor de íons cloreto na água. Do ponto de vista dos produtos de corrosão formados, após dois anos de ensaio, constatou-se que a rede I (fluxo correto e circulação de água), foi a única sobre a qual se formou uma carmada de produtos de corrosão homogênea.

\section{DISCUSSÃO DOS RESULTADOS}

Os exames, análises e ensaios realizados levaram a concluir que as perfurações observadas na tubulação de cobre da rede de sprinklers foram provocadas pelo excesso de fluxo de solda utilizado durante a soldagem dos tubos, associada à falta de circulação de água. De fato, verificou-se que as perfuraçôes foram causadas por pites localizados nas bordas das manchas formadas a partir do escorrimento do fluxo de solda utilizado em excesso, o qual continha em sua composição o elemento cloro. A presença deste fluxo em excesso e a falta de circulação não permitiram a formação de uma camada de óxidos de caráter protetor na superfície do cobre, responsável pelo bom desempenho deste metal. Os ensaios de simulação mostraram claramente isto: somente na rede I, onde o fluxo foi aplicado corretamente e a água circulou, foi formada uma camada de produtos de corrosão esverdeados (típicos produtos de corrosão do cobre) cobrindo toda a superfície dos tubos ensaiados.

Sabe-se que a resistência à corrosão de uma tubulação de cobre, quando utilizada na condução de água, é garantida pela formação de uma camada uniforme, compacta e aderente, constituída basicamente de óxido cuproso, que age como uma barreira entre o metal e o meio de exposição (água). No entanto, se esta barreira apresentar descontinuidades, ou se suas características protetoras não puderem ser

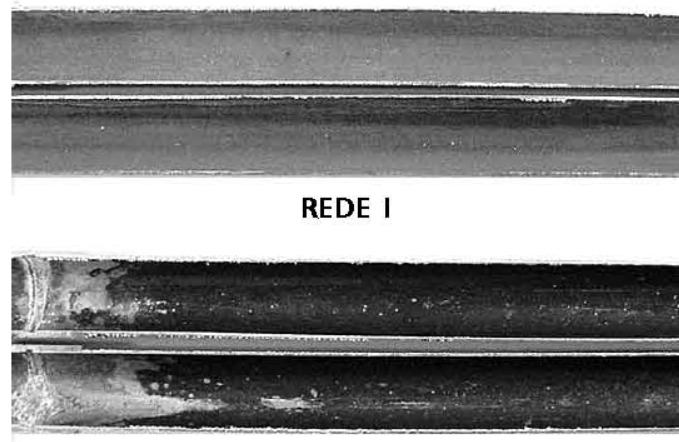

REDE 2

Figura 3. Aspecto da superfície interna de tubos das redes I e 2. Observa-se, na rede I (fluxo aplicado corretamente, água circulando), uma camada uniforme de produtos de corrosão esverdeados e, na rede 2 (fluxo aplicado corretamente, sem circulaçäo), uma camada de produtos de corrosão escuros com manchas de escorrimento de fluxo.

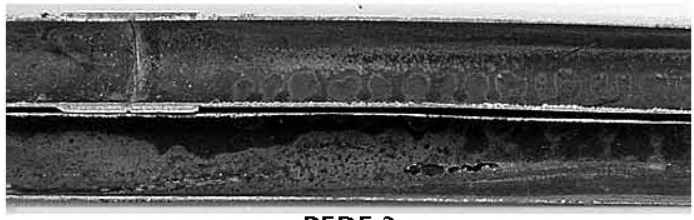

REDE 3



REDE 4

Figura 4. Aspecto da superfície interna de tubos das redes 3 e 4. Observa-se, na rede 3 (fluxo em excesso, água circulando), uma camada näo-uniforme de produtos de corrosäo esverdeados e, na rede 4 (fluxo em excesso, sem circulaçäo), uma camada de produtos de corrosão incolores com escorrimento de fluxo na regiäo de solda. 
mantidas, o cobre e suas ligas poderão sofrer corrosão tanto generalizada como localizada. Neste último caso, a corrosão por pite constitui uma das formas mais comuns de ataque localizado do cobre em contato com a água. Alguns autores $^{(2)}$ citam a presença de resíduos na superfície da tubulação de sprinklers e uma pobre drenagem como causadores de problemas de corrosão, conforme ocorreu no caso em estudo. Myers e Cohen ${ }^{(3)}$ afirmam que $15 \%$ a $20 \%$ dos casos de falha em tubulação de cobre são causados pelo uso de excesso de fluxo de solda. De acordo com estes autores, uma vez iniciado o processo de corrosão devido à presença do fluxo de solda (ou de seu ingrediente ativo presente, no caso, o cloro), a ocorrência dos pites é facilitada pela presença de oxigênio dissolvido na água, assim como pela formação de ácido clorídrico no interior do pite.

Para minimizar falhas do tipo em estudo, são feitas normas orientativas como a Norma ASTM B 828:00(4). Segundo esta Norma, o fluxo de solda deverá ser aplicado com pincel na forma de uma fina carnada. Na prática, no entanto, é comum a imersão da ponta do tubo a ser soldado no fluxo de solda, o que acarreta um excesso de fluxo retido na tubulação, após soldagem. Ao ser aquecido, este fluxo escorre pelo interior do tubo, criando uma trilha de pites localizados na periferia do sentido do escorrimento do resíduo. Desta forma, é possível identificar os pites induzidos por fluxo de solda por análise de energia dispersiva: o elemento cloro é detectado no interior dos pites. Isto é muito importante, tendo em vista que estudos ${ }^{(5)}$ mostram que, nos últimos anos, houve um aumento nos casos de corrosão causados por fluxo de solda. Conhecido no exterior, este tipo de falha começou a se tornar freqüente no Brasil ao final da década passada, passados alguns anos do início da utilização de tubos de cobre em redes de sprinklers.

É importante ressaltar que uma circulação eficiente da água poderá contrapor a ação nociva do fluxo em excesso(6). Para tal, a norma ASTM B 813:00(7), que trata das características dos fluxos de solda, especifica que seu resíduo deve ser lavável e não-corrosivo. Para verificar esta agressividade, recomenda a realização de um ensaio específico. Assim, considerando o grande número fluxos de solda à venda no mercado, é possível buscar, dentre eles, um fluxo com características menos-agressivas.
A questão da lavabilidade do fluxo ficou bem caracterizada no presente estudo. Segundo informaçôes fornecidas pelos representantes do edifício, a tubulação de água potável também era composta por tubos de cobre, e estes não apresentaram problemas após três anos de uso. Este fato está diretamente relacionado com a lavagem dos resíduos do fluxo. Muito provavelmente, os resíduos do fluxo utilizado na tubulação de cobre em estudo eram laváveis, razão da não-perfuração da tubulação de água potável: neste caso, a água circulou e removeu os resíduos do fluxo, ao passo que no caso da rede de sprinklers a água ficou estagnada. Cohen ${ }^{(8)}$, em seu trabalho, conclui que para minimizar os efeitos do fluxo de solda, os sistemas devem ser lavados e mantidos limpos logo após a sua instalação. Manuais de instalação de tubulação de cobre, fornecidos por vários municípios dos Estados Unidos, também reforçam que toda tubulação deve ser limpa, pela circulação de água, antes que a mesma entre em funcionamento ${ }^{(9)}$.

Esse fato também foi claramente ilustrado pelos ensaios de simulação, nas quais se verificou que nos tubos onde houve estagnação da água (redes 2 e 4) ou onde o fluxo foi aplicado em excesso (redes 3 e 4), não houve a formação de uma camada uniforme no interior da tubulação. No caso da rede 3 , análises metalográficas realizadas permitiram constatar que os pontos escuros são regiōes com corrosão localizada, presentes na superfície interna do tubo. Assim, é de se esperar que este processo de corrosão localizada evolua, formando pites e perfurando o tubo.

É importante ressaltar que o fluxo de solda nem sempre é o causador da corrosão. Qualquer sujidade presente no interior da tubulação também pode impedir a formação de uma camada uniforme de produtos de corrosão do cobre de caráter protetor. No caso em estudo, foram identificados elementos que indicam a presença de sujidades retidas na superfície interna do tubo (cálcio, silício e carbonato de cálcio). Assim, a presença destas sujidades onde a água não circulava também contribuiu para a ocorrência de um processo de corrosão localizada no interior da tubulação.

Além das análises na tubulação de cobre, também foram realizadas análises químicas das amostras de água, com o intuito de verificar sua possível influência na corrosão ocorrida na tubulação da rede de sprinklers. Para poder discutir a influência da água no processo corrosivo do presente estudo, convém fazer algumas consideraçỗes a respeito dos mecanismos de corrosão do cobre em contato com água potável. Conforme já dito, a resistência à corrosão dos tubos de cobre em água potável está diretamente relacionada com a formação de uma camada uniforme de produtos de corrosão insolúveis. Se a água não for capaz de formar produtos de corrosão insolúveis, o cobre pode sofrer intensa corrosão generalizada. Se, por outro lado, a água for capaz de formar produtos de corrosão insolúveis, o cobre poderá apresentar um excelente desempenho, se a camada formada for compacta e uniforme, ou poderá apresentar corrosão localizada por pite, se a camada formada não for compacta e uniforme e/ou se esta camada sofrer danificação localizada. De acordo com a literatura, as características da água devem ser consideradas em função do tipo 
de corrosão. Assim, os parâmetros considerados para a ocorrência de corrosão generalizada são diferentes dos parâmetros correlacionados com a corrosão localizada do tipo pite. Também se deve levar em conta a temperatura da água, se é fria ou quente. Para o caso de corrosão generalizada e corrosão por pite em água quente, existe um consenso sobre os parâmetros a serem considerados para verificar a agressividade da água. No entanto, há muita controvérsia quanto aos parâmetros a serem considerados quando a corrosão é por pite em água fria, existindo inclusive autores ${ }^{(10)}$ que afirmarn que esta questão não está ainda bem definida. $\mathrm{Na}$ realidade, a principal razão da ocorrência de corrosão por pite em água fria está relacionada com o estado da superfície do cobre antes de entrar em contato com a água. Sujidades presentes, provenientes do processo de instalação da tubulação de cobre, tais como resíduos de material de construção e metal e fluxo de solda, agem como agentes que impedem a formação de uma camada com características protetoras. Isto significa que uma mesma água pode determinar a corrosão por pite em uma tubulação e não em outra. Isto, inclusive, explica as controvérsias encontradas na literatura.

\section{CONCLUSÕES}

Com base no caso estudado e nos exames e análises realizados em laboratório, conclui-se que a corrosão constatada na rede de sprinklers [MLKI]do caso em estudo foi determinada pelo uso excessivo de fluxo de solda de características agressivas durante a montagem da rede, somado à presença de sujidades remanescentes no interior da tubulação e a condição de estagnação da água no interior da rede de sprinklers. Nos ensaios em laboratório, constatou-se que a aplicação de fluxo de solda em excesso alterou significativamente os parâmetros da água retida no interior dos tubos, além de determinar a formação de uma carnada de produtos de corrosão não-uniforme no interior dos tubos, prejudicando suas características protetivas.

\section{REFERÊNCIAS}

I. FISCHER, W.R.; WAGNER, D.; SIEDLAREK, H. - Microbiologically Influenced Corrosion in Potable Water Installations - An Engineering Approaching to Developing Countermeasures. Materials Performance, v. 34, n. I0, p. 50-54, October 1995

2. WAGNER, J.; YOUNG, W.T. - Corrosion in building water systems. Materials Performance, USA, V. 29, n. 10, p. 4046, Oct. 1990.

3. MYERS, J.R.; COHEN, A. Soldering Flux-Induced pitting of Copper Water Lines. Materials Performance, USA, V. 33, n. 10, P. 62-63, Oct. 1994.

4. AMERICAN NATIONAL STANDARDS INSTITUTE. ASTM B 828-02: Standard practice for making capillary joints by soldering of copper and copper alloy tube and fittings. Washington, 2000.

5. MICHELS, H.T. How the copper industry helps solve corrosion problems. Disponível: <http://environment.copper.org/NACE02122/intro.html\#abstract>. Acesso em 13 jun. 2003, I1:23.

6. CHARLTON, R.S, - Failures of copper potable water piping due to design, materials and poor workmanship. NACE International Corrosion 200 I, NACE International, Houston, Texas, USA, II-I6 Mar. 33 pp. 200 I.

7. AMERICAN NATIONAL STANDARDS INSTITUTE. ASTM B 8I3-00el - Standard especification for liquid and paste fluxes for soldering of copper and copper alloys. Washington, 2000.

8. COHEN, A., - Flux Corrosion of copper plumbing Systems. Proceedings of International Symposium on Corrosion of Copper and Copper Alloys in Buildings, Japan Copper Development Association, Tokyo, Japan, 1982, pp. 47-59.

9. Palo Alto RWQCP Guidelines for Designers, Installers, \& Owners. of. Copper Piping Systems <http://www.city.paloalto.ca.us/cleanbay/pdf/cuguidelines.pdf > . Acesso em 09 maio 2005, 13:35h.

I0. BROO, A.E., BERGHULT, B., HEDBERG, T. - Copper Corrosion in drinking water distribution systems - The influence of water quality. Corrosion Science, v. 39, n. 6, p. II I9- II 32, June 1997.

Recebido em: 02/03/05

Aceito em: 02/09/05

Proveniente de: CONGRESSO ANUAL DA ABM - INTERNACIONAL, 59., 2004, São Paulo - SP. São Paulo : ABM, 2004. 